\title{
Variation of Carotenoids and Polyphenolics in Peach and Implications on Breeding for Modified Phytochemical Profiles
}

\author{
Allan F. Brown', Gad G. Yousef, Ivette Guzman, and Kranthi K. Chebrolu \\ Plants for Human Health Institute, Department of Horticultural Science, North Carolina Research \\ Campus, North Carolina State University, 600 Laureate Way, Kannapolis, NC 28081 \\ Dennis J. Werner and Mike Parker \\ Department of Horticultural Science, North Carolina State University, Raleigh, NC 27695 \\ Ksenija Gasic \\ School of Agricultural, Forest, and Environmental Science, Clemson University, Clemson, SC 29634 \\ Penelope Perkins-Veazie \\ Plants for Human Health Institute, Department of Horticultural Science, North Carolina Research \\ Campus, North Carolina State University, 600 Laureate Way, Kannapolis, NC 28081
}

\begin{abstract}
Additional INDEX wORDs. anthocyanin proanthocyanidin, chlorogenic acid, quercetin, xanthophyll, $\beta$-carotene, Prunus persica

Abstract. The objective of this study was to examine the relative impact of genetics and environment on phenolic and carotenoid profiles in peach (Prunus persica) germplasm. Fully mature, ("ready-to-eat" stage) firm fruit of peach cultivars China Pearl, Contender, and Carolina Gold were collected from established trees at two North Carolina locations in 2009 and 2010. Advanced breeding selections NC Yellow and NC 97-48 were collected from a single location in both years. Using tandem extractions and chromatography analyses, 10 carotenoids and 24 phenolic compounds were quantified separately in the peel and flesh. Statistically significant differences were noted among peach cultivars and advanced selections for $\beta$-carotene, cyanidin-3-glucoside, cyanidin-3-rutinoside, cholorogenic acid, quercetin-3-glucoside, and individual procyanidins. Peel anthocyanin (ANC) concentration ranged from 183 $\mathrm{mg} / 100 \mathrm{~g}$ in 'Contender' to non-detectable levels in NC97-48 and NC Yellow. 'China Pearl' and 'Carolina Gold' produced ANC levels approximately half of 'Contender'. Chlorogenic acid concentration also fit a discrete pattern of accumulation but was not related to the accumulation of ANC. 'China Pearl', NC 97-48, and NC Yellow contained the highest levels of chlorogenic acid (105 to $136 \mathrm{mg} / 100 \mathrm{~g})$, 'Carolina Gold' contained the lowest $(52 \mathrm{mg} / 100 \mathrm{~g}), \mathrm{and}$ 'Contender' represented an intermediate phenotype $(70 \mathrm{mg} / 100 \mathrm{~g})$. Statistically significant genetic variation was found for almost all compounds identified, whereas location and year effects tended to be compound-specific. For chlorogenic acid, $28 \%$ of the phenotypic variance was explained by location (year $=$ nonsignificant), whereas $40 \%$ of the phenotypic variation of ANC was explained by differences in years (location = nonsignificant). Analyzing fruit from the same environment over 2 years or from two locations in the same year would not have adequately accounted for the variation associated with environment. The detailed phytochemical profile of peach reported here demonstrates the importance of multiyear, multilocation analysis in revealing accurate measures of phytochemical genetic variation and provides a comprehensive baseline analysis of phytochemicals in commonly grown peach cultivars that can be used to evaluate novel germplasm.
\end{abstract}

Epidemiological studies have suggested that increased consumption of fruits and vegetables is associated with decreased risks of chronic diseases such as cancer, diabetes, and cardiovascular disease (Arts and Hollman, 2005). It has further been suggested that these beneficial properties in fruits are largely attributable to their antioxidant capacity (Halliwell, 1996). This has led to calls from some quarters to develop peach cultivars with higher levels of total antioxidant capacity (TAC), which is measured with various chemical assays (Dalla Valle et al., 2007; Vizzotto et al., 2007). To this end, surveys of peach germplasm have identified differences in TAC as well as

Received for publication 12 May 2014. Accepted for publication 25 Aug. 2014. Funding for this study was provided by the University of North Carolina General Administration Special Allocation for Collaborative Research at the North Carolina Research Campus, NC.

${ }^{1}$ Corresponding author. E-mail: afbrown2@ncsu.edu. differences in total phenolics and/or total anthocyanin, thought to be the primary contributors to these measurements in peach (Cantín et al., 2009; Dalla Valle et al., 2007; Gil et al., 2002; Vizzotto et al., 2007).

Current medical studies suggest that associations between generalized plant measurements of TAC and recognized human biomarkers of disease or definitive health endpoints are limited, inconsistent, and often inconclusive (Chong et al., 2010). A recent review of cardiovascular disease and foods concluded that although some polyphenol-rich foods exert beneficial effects on health, there is no clear evidence that this is associated with general antioxidant capacity (Hollman et al., 2011). Long-term epidemiological studies of prostate cancer and cognitive decline have also come to similar conclusions (Devore et al., 2013; Russnes et al., 2014). Likely, the relationship between plant compounds and human health is more complex than has been previously assumed and involves 
multiple modes of action including the modulation of a wide range of enzymes and cell receptors, differences in bioactivity and potency among individual compounds, differences in bioavailability in the human digestive system, and synergistic interactions among individual compounds (Chong et al., 2010; Gordon, 2011; Hollman et al., 2011; Vauzour et al., 2010).

Noratto et al. (2009), for example, observed differences in the bioactivity of fractioned phenolics from peaches in the suppression of estrogen-independent breast cancer cells. The fractions represented phenolic acids, ANC, flavonols, and procyanidins and displayed distinct differences in both the suppression of the estrogen-independent breast cancer lines and in toxicity toward normal breast epithelial cells. What this suggests is that the presence or absence of individual components of the phytochemical profiles of peach may have greater impact on health than generalized measurements of TAC. Understanding how these individual compounds are accumulated and identifying sources of genetic variation could greatly assist medical research and lead to the eventual identification of specific phytochemical phenotypes in peach tailored to enhance human health.

The polyphenolic profile of the peel and flesh of peach includes hydroxycinnamates (chlorogenic and neochlorogenic acid), flavan 3-ols (catechin, epicatechin, procyanidins), flavonols (quercetin 3-glucoside and 3-rutinoside), and ANC (cyanidin 3glucoside and 3-rutinoside) (Tomás-Barberán et al., 2001). The carotenoid profile of peach includes $\beta$-carotene, $\beta$-cryptoxanthin, lutein, zeaxanthin, and lesser amounts of additional related compounds (Dalla Valle et al., 2007). As would be expected, yellow-fleshed peaches generally contain $\approx 10$-fold levels of $\beta$-carotene and $\beta$-cryptoxanthin than their white-fleshed counterparts, where generally only trace amounts are found.

To our knowledge, only a single survey of peach phenolic variation has been replicated over years (Cantín et al., 2009), which prevents an accurate assessment of the genetic and environmental components of the observed variation. No study has yet compared the relative impact of years and locations on the accumulation of phenolics or carotenoids in peach. An additional concern is that previous studies have generally bulked fruit samples from the same tree or same cultivar, which could potentially inflate the estimate of random error and provide inaccurate estimations of the genetic differences among cultivars.

In this study we used a tandem extraction and chromatography analyses for phenolics and carotenoids in the peel and flesh of replicated individual fruit of peach cultivars with known color mutations (or mutations in their pedigree). The material was obtained from two diverse North Carolina locations over 2 years. The objectives were to first provide a detailed baseline phytochemical profile of carotenoids and phenolics in peach that could be used as a reference for future studies and second to determine the relative impact of year and location on discerning genetic variability in phytochemical profiles.

\section{Materials and Methods}

STANDARDs. Commercial carotenoid standards of $\beta$-carotene were purchased from Sigma-Aldrich (St. Louis, MO), and standards of lutein, epoxy lutein, violaxanthin, neoxanthin, and $\beta$-cryptozanthin were purchased from Carote-Nature (Lupsingen, Switzerland). Six concentrations of carotenoid standards were dissolved in ethanol and diluted in hexane.
Standard concentrations were determined spectrophotometrically using their respective molar extinction coefficients (Rodriguez-Amaya, 2001). Commercial flavonoid standards of procyanidins (B1 and B2), catechin, epicatechin, chlorogenic acid, quercetin glycosides, and cyanidin glycosides were purchased from Chromadex (Irvine, CA). Neochlorogenic acid was purchased from Sigma-Aldrich. Five flavonoid standard concentrations were prepared in 50\% methanol to generate standard curves. Five microliters of each standard were injected as an external standard followed by the peach extract samples. Methanol, acetonitrile, formic acid, and acetic acid were purchased from Fisher Scientific (Pittsburgh, PA). All solvents were of high-performance liquid chromatography (HPLC) or HPLC-mass spectrometry (MS) grades.

Plant materials. Tree-ripened fruit ("ready-to-eat" stage) of three peach cultivars, China Pearl, Contender, and Carolina Gold, were collected from established trees at two North Carolina State University (NCSU) agricultural research stations located in Mills River and Jackson Springs, NC, in 2009 and 2010. The Mills River site (lat. $35.41^{\circ} \mathrm{N}$, long $79^{\circ} \mathrm{W}$ ) is located in the mountains of western North Carolina, at an elevation of $884 \mathrm{~m}$, with a clay-loam soil type. The Jackson Springs site (lat. $35^{\circ} \mathrm{N}$, long. $82^{\circ} \mathrm{W}$ ) is located in the Sandhills region of the southern piedmont of North Carolina. The elevation at this site is $191 \mathrm{~m}$. Soils are predominantly coarse-textured sand demonstrating excellent drainage and low moisture-holding capacity. Trees at the two locations differed by age. All trees at Mills River were planted in 2001, whereas trees at Sandhills were planted in 2001 ('China Pearl'), 2005 (NC Yellow and NC 9748), and 2006 ('Contender' and 'Carolina Gold'). All trees were considered "mature" in that they had completed at least five growing seasons by the first year of analysis. Standard cultivation and fertility practices were followed at both sites.

Contender is a high-chilling yellow-fleshed freestone cultivar widely grown in North Carolina and extensively used in cultivar development (Werner et al., 1989). 'China Pearl' is a white-fleshed peach resulting from the hybridization of 'Contender' (yellow flesh) and a white-fleshed Chinese introduction PI 134401 (Werner and Snelling, 2006). In addition to white flesh, PI 134401 (not included in the study) lacks red coloration in the peel and likely contains a recessive mutation for ANC accumulation in that tissue. 'Carolina Gold' is a yellow-fleshed freestone peach developed through the hybridization of 'Biscoe' $\times$ NC-C5S-067. The pedigree of NCC5S-067 is 'Encore' $\times$ Calanda San Miquel 2383 (Werner and Snelling, 2006). Calanda San Miquel 2383 is a yellow-fleshed, Spanish land race that lacks ANC in the fruit and the peel. In addition to the three commercial cultivars, two NCSU advance breeding selections (NC 97-48 and NC Yellow) were also collected from the Jackson Springs site in 2009 and 2010 (not available at second location). Both selections share the same pedigree 'Contender' $\times$ P I65977 but may have been derived from different $\mathrm{F}_{1}$ plants. A complete discussion of $\mathrm{PI}$ accessions has been previously published (Werner and Okie, 1998). Pedigree information for the peach genotypes evaluated in this study is presented in Figure 1.

Fruit of each cultivar were collected from the peak harvest of four pre-labeled trees at each location. Fruit was immediately placed in ice coolers and transported to the Plants for Human Health Institute, NCSU at Kannapolis, NC, where they were processed the same day. Five representative fruit from each tree were selected at random from the peak yield to randomize 

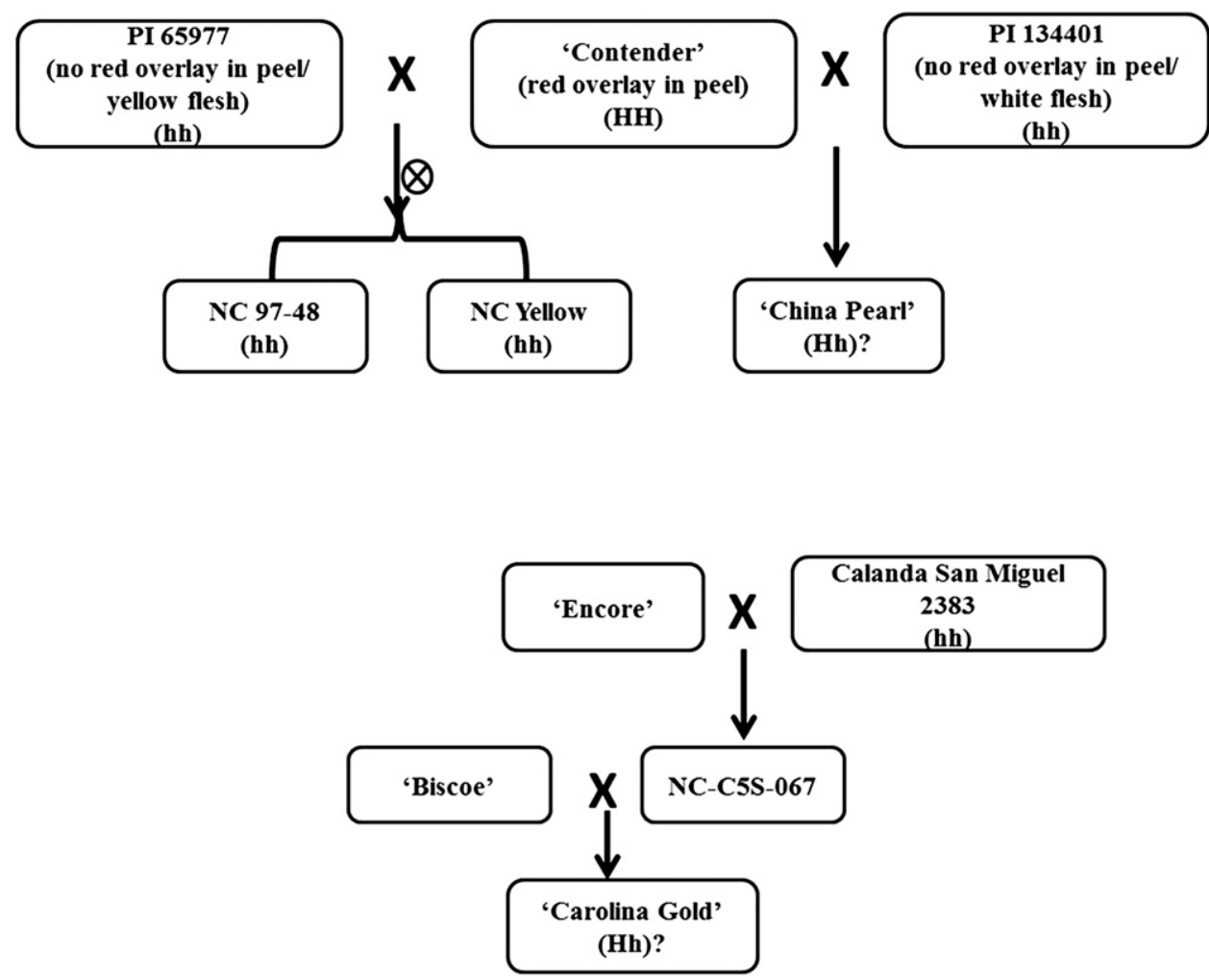

Fig. 1. Pedigree information for 'China Pearl', NC 97-48, NC Yellow, and 'Carolina Gold' peach evaluated for carotenoids and flavonoids in 2009 and 2010, Salisbury, NC. Proposed genotypes of the "Highlighter" gene (hh) are shown in parentheses.

positional effects. After weighing individual fruit, the fruit was bisected and the peel was separated from flesh. Peel and fruit were individually flash-frozen in liquid nitrogen and stored at $-80{ }^{\circ} \mathrm{C}$. Weights of the pit, peel, scar, and flesh were recorded. The total soluble solids were measured using a handheld digital refractometer (PAL-1; Atago, Tokyo, Japan). Frozen fruit peel and flesh were freeze-dried using a freeze dryer (VirTis 24Dx48; SP Scientific, Stone Ridge, NY) and the lyophilized tissue was then ground into fine powder with a coffee grinder and stored at $-20^{\circ} \mathrm{C}$ in the dark until analyses for carotenoids and flavonoids. Moisture removed from samples after freezedrying was estimated to be $87.2 \% \pm 2.9 \%$ and $85.2 \% \pm 2.1 \%$ in the flesh and peel, respectively.

EXTRACTION AND ANALYSIS OF CAROTENOIDS. Under yellow lights, $0.2 \mathrm{~g}$ of freeze-dried finely ground tissue was placed in $50-\mathrm{mL}$ tubes and extracted three times with $5 \mathrm{~mL}$ hexane for $20 \mathrm{~min}$ on a standard laboratory shaker $(180 \mathrm{rpm})$. The extracts were then centrifuged at $2900 g_{\mathrm{n}}$ for $15 \mathrm{~min}$ at $10^{\circ} \mathrm{C}$ and supernatants were collected in new $50-\mathrm{mL}$ tubes for carotenoid quantification. After carotenoid extraction, the pellets were completely dried down under a stream of nitrogen gas for flavonoid extraction as described below. The supernatant (hexane containing carotenoids) was saponified by adding methanolic $0.1 \% \mathrm{KOH}$ at $60{ }^{\circ} \mathrm{C}$ for $45 \mathrm{~min}$. A half volume of water was added to remove lipids and $\mathrm{KOH}$ and samples were centrifuged where the top layer of hexane was pipetted into a new $15-\mathrm{mL}$ tube. Samples were dried down completely under nitrogen gas and re-suspended in $1.5 \mathrm{~mL}$ ethanol. The ethanolic extracts were filtered through $0.2-\mu \mathrm{m}$ polytetrafluoroethylene (PTFE) filters (Nalgene, Rochester, NY) into amber 2-mL amber vials and stored under nitrogen gas at $-80{ }^{\circ} \mathrm{C}$ until analysis.
Carotenoids were separated on a $1.8-\mu \mathrm{m}, 2.1 \times 100-\mathrm{mm}$ column (HSS T3; Waters, Milford, MA) set at $35^{\circ} \mathrm{C}$ using an ultra-performance liquid chromatography (UPLC) unit (ACQUITY; Waters) with a photodiode array detector. The UPLC analysis was conducted following procedures previously described (Guzman et al., 2012). The solvent system consisted of A) $0.05 \%$ ammonium acetate and B) 74:19:7 $(\mathrm{v} / \mathrm{v} / \mathrm{v})$ acetonitrile:methanol:chloroform. The profile included two linear phases ( 0 to $18 \mathrm{~min}$ at $75 \% \mathrm{~B}, 18$ to $19 \mathrm{~min}$ from $75 \%$ to $100 \% \mathrm{~B}, 19$ to $30 \mathrm{~min}$ from $100 \%$ to $98 \% \mathrm{~B}$ ). Flow rate was set at $0.4 \mathrm{~mL} \cdot \mathrm{min}^{-1}$ and the injection volume was $5 \mu \mathrm{L}$. Spectra were observed for the wavelengths between 240 and $500 \mathrm{~nm}$ and carotenoids were detected at $450 \mathrm{~nm}$ and identified according to retention time and spectral comparison with commercial standards and published data.

EXTRACTION AND ANALYSIS OF PHENOLIC COMPOUNDS. The dried pellets of peel and flesh (after carotenoid extraction) were used to extract flavonoids from the individual fruit. A single sample was used for both extractions as a result of the limited amount of tissue represented by the peel. For flavonoid extraction, $0.5 \mathrm{~g}$ of dry pellet was extracted with $5 \mathrm{~mL}$ of $47.5 \%$ methanol $(\mathrm{MeOH}), 47.5 \%$ water, and $5 \%$ formic acid twice $(10 \mathrm{~mL}$ total $)$ with incubation on ice for $20 \mathrm{~min}$ and occasional vortexing. The mixture of sample and solvent was centrifuged $\left(2900 \mathrm{~g}_{\mathrm{n}}, 10{ }^{\circ} \mathrm{C}, 20 \mathrm{~min}\right)$ and supernatant was collected with $1.5 \mathrm{~mL}$ filtered through a $0.2-\mu \mathrm{m}$ PTFE syringe filters (Fisher Scientific, Pittsburgh, PA). Samples were stored at $-20{ }^{\circ} \mathrm{C}$ until further analysis. For each sample, $15 \mu \mathrm{L}$ was injected into the HPLC attached to a quadratic time of flight (QTOF) MS (6510; Agilent Technologies, Santa Clara, CA) for chromatography separation. The HPLC was an Agilent 1200 system with a temperature-controlled autosampler and column compartment. The system was equipped with reversed-phase $\mathrm{C}_{18}$ column (Zorbax ods, $250 \times 4.6 \mathrm{~mm} 5 \mu \mathrm{M}$; Agilent Technologies). The solvents used were A) $5 \%$ formic acid and $\mathrm{B}) 100 \% \mathrm{MeOH}$. The gradient was $5 \% \mathrm{~B}(5 \mathrm{~min}), 10 \% \mathrm{~B}$ (10 min), 15\% B (10 min), 25\% B (5 min), 60\% B (15 min), and $5 \% \mathrm{~B}(15 \mathrm{~min})$ with a constant flow rate of $1 \mathrm{~mL} \cdot \mathrm{min}^{-1}$. Simultaneously, flavan-3-ol, phenolic acids, flavonol, and ANC were separated and quantified using their maximum ultraviolet absorption with this analysis protocol. Flavan-3-ol compounds including the proanthocyanidins (catechin, epicatechin, and procyanidins B1, B2, B3, and B4) as well as other flavan-3-ols were monitored at maximum ultraviolet wavelength absorption of $280 \mathrm{~nm}$. Phenolic acids including chlorogenic, neochlorogenic, and caffeic acids were monitored at ultraviolet $325 \mathrm{~nm}$. Flavonols including quercetin glycosides (glucoside and rutinoside) and other quercetin derivatives were recorded at ultraviolet $360 \mathrm{~nm}$. ANC, including cyanidin glycosides (glucoside 
and rutinoside), were monitored at ultraviolet $520 \mathrm{~nm}$. Identification of compounds was established by using authentic standards (Chromadex), molecular weights recorded on HPLC-MS-QTOF, and comparison with published data (de Pascual-Teresa et al., 2000; Gu et al., 2004; Haminiuk et al., 2012; Hong et al., 2004; Lavelli et al., 2009; Tomás-Barberán et al., 2001).

Statistical analyses. Analysis of variance (ANOVA) was performed using the general linear model procedure (PROC GLM) to estimate variation associated with each source of variation using SAS software (Version 9.3; SAS Institute, Cary, NC). The ANOVA was limited to cultivars grown in both environments ('Contender', 'China Pearl', and 'Carolina Gold'). For carotenoids and flavonoids quantified in peach peel or flesh, the statistical model used was $\mathrm{y}_{\mathrm{ijkl}}=\mu+\mathrm{Y}_{\mathrm{i}}+\mathrm{L}_{\mathrm{j}}+\mathrm{C}_{\mathrm{k}}+$ $\mathrm{YC}_{\mathrm{ik}}+\mathrm{LC}_{\mathrm{jk}}+\mathrm{YL}_{\mathrm{ij}}+\mathrm{LYC}_{\mathrm{ijk}}+\mathrm{T}(\mathrm{C})_{(\mathrm{k}) 1}+\mathrm{F}(\mathrm{T})_{(\mathrm{l}) \mathrm{m}}+\varepsilon_{(\mathrm{ijklm})}$, where $\mathrm{y}=$ response from the experimental unit, $\mu=$ overall mean, $\mathrm{Y}=$ year, $\mathrm{L}=$ location, $\mathrm{C}=$ genotype, $\mathrm{T}(\mathrm{C})=$ tree within genotype, $\mathrm{F}(\mathrm{T})=$ fruit within tree, and $\varepsilon=$ experimental random error. Pearson correlation statistics were generated using the PROC CORR module of the same software and was also limited to the three cultivars grown in both locations. Tukey's honest significant test was used to compare significance differences among cultivars at $P<0.5$. The PROC MEANS statement was used to compute cultivar means and SDS over the 2 years, 2009 and 2010. Carotenoid concentrations were presented as micrograms per gram dry weight (DW), whereas flavonoids were presented as milligrams per $100 \mathrm{~g} \mathrm{DW}$ in the peel and flesh of individual peach fruit.

\section{Results}

Tandem UPLC and HPLC-MS analysis revealed appreciable levels of 10 carotenoids and 24 phenolic compounds (Fig. 2) in the peel and/or flesh of the three peach cultivars and two advanced selections. Seven carotenoids could be identified on the basis of available standards and included neoxanthin, violaxanthin, lutein epoxide, lutein, zeaxanthin, $\beta$-cryptoxanthin, and $\beta$-carotene. Three additional minor peaks were identified in both the peel and the flesh but represented relatively minor contributions to overall carotenoid levels. The predominant carotenoid found in both the flesh and peel was violaxanthin, which tended to be two to three times higher than other identified carotenoids. A 3-fold difference was observed in total carotenoids between 'China Pearl' and yellow-fleshed peaches. Although all carotenoids were appreciably lower in 'China Pearl', the greatest differences were observed with xanthophylls. Violaxanthin accumulation was six times lower in the flesh and 10 times lower in the peel. A reduction in unidentified carotenoids was even more dramatic with an almost 20-fold decrease in both the flesh and peel. Neoxanthin was not detected in either the flesh or peel of 'China Pearl'. The yellow-fleshed cultivars were not significantly different from each other in the accumulation of total or individual carotenoids in either the peel or flesh.

The phenolic content included two major ANCs (cyanidin 3glucoside and cyanidin 3-rutinoside), three phenolic acids (chlorogenic, neochlorogenic, and caffeic acid), and 14 flavan-3-ols \{catechin, epicatchin, procyanidin B1-B4 [B1 = epicatechin$(4 \beta \rightarrow 8)$-catechin, B2 = (-)-epicatechin- $(4 \beta \rightarrow 8)-(-)$-epicatechin, $\mathrm{B} 3=$ catechin- $(4 \alpha \rightarrow 8)$-catechin, and B4 = catechin- $(4 \alpha \rightarrow 8)$ epicatechin]\}. The unidentified eight flavan-3-ols represented relatively minor peaks in the phenol profile. The flavanol profile included quercetin-3-glucoside, quercetin-3-rutinoside, and three unidentified minor peaks.

ANC concentration in the peel (primarily cyanidin 3glucoside) ranged from undetectable levels (NC Yellow and NC 97-48) to $178 \mathrm{mg} / 100 \mathrm{~g} \mathrm{DW}$ ('Contender') (Table 1). 'Contender' contained significantly higher levels of cyanidin 3glucoside than 'China Pearl' or 'Carolina Gold' (approximately two times), which were not significantly different from each other. ANCs were not detected in the flesh of any genotype (Table 2). Chlorogenic acid was the primary phenolic acid detected in the peel and in general was four to five times higher than neo-chlorogenic acid (Table 1). A 2- to 3-fold variation (52 to $136 \mathrm{mg} / 100 \mathrm{~g} \mathrm{DW}$ ) among cultivars was observed with 'China Pearl', NC Yellow, and NC 97-48 containing significantly higher levels than 'Contender' or 'Carolina Gold'. Chlorogenic acid was present in the flesh at lower concentrations but a similar ranking of the cultivars was apparent with NC Yellow and NC 97-48 containing the highest levels and 'Contender' and 'Carolina Gold' accumulating the lowest levels.

Flavonols constituted a relatively minor contribution to total phenolic concentration in both the peel and the flesh. The predominant flavonols identified in the peel were identified as quercitin-3-glucoside and quercitin-3-rutinoside in approximately equal concentrations. Significant (2-fold) differences in quercetin-3-glucoside accumulation in the peel were noted between 'China Pearl' ( $8 \mathrm{mg} / 100 \mathrm{~g} \mathrm{DW}$ ) and NC Yellow and NC 97-48 (16 to $19 \mathrm{mg} / 100 \mathrm{~g} \mathrm{DW})$. Flavonols were present in the flesh but at lower concentrations. The flavan-3-ol profile of peach included: catechin, epicatechin, and 12 proanthocyanidin dimers and polymers. The predominant procyanidins were identified as B1 [epicatechin- $(4 \beta \rightarrow 8)$-catechin], B2 [(-)-epicatechin$(4 \beta \rightarrow 8)-(-)$-epicatechin], and B3 [catechin- $(4 \alpha \rightarrow 8)$-catechin]. In general, 'Carolina Gold' tended to have lower levels of most of these compounds but these differences were not in general significant.

The ANOVA conducted on cultivars replicated at both locations over 2 years ('Contender', 'China Pearl', and 'Carolina Gold') detected significant genetic variation for all compounds except catechin, procyanidin B4, and the unidentified flavonol derivatives (Tables 3 and 4). Of the five major phenolic compounds found in peach (cyanidin 3-glucoside, chlorogenic acid, catechin, and procyanidins B1 and B3), only catechin was nonsignificant for genetic variation. The genetic variation associated with cyanidin 3-glucoside and chlorogenic acid was $20 \%$ and $40 \%$, respectively. The relative importance and significance of location and year effects was compoundspecific. Location effects contributed $28 \%$ of the variation associated with chlorogenic acid (year nonsignificant), whereas year contributed $35 \%$ of the variation associated with cyanidin 3-glucoside (location nonsignificant). Significant two- and three-way interactions were detected for multiple compounds. The relative magnitude of these effects depended on the individual compound. No significant variation could be detected $(P<0.01)$ for any compounds between fruit from the same tree or trees of the same cultivar within environments.

Moderate to nonsignificant correlations were observed among polyphenolic concentrations of 'Contender', 'Carolina Gold', and 'China Pearl' across locations and years (Table 5). The strongest correlations tended to occur between constituents of the same flavonoid class (neochlorogenic and chlorogenic acid $=r$ 

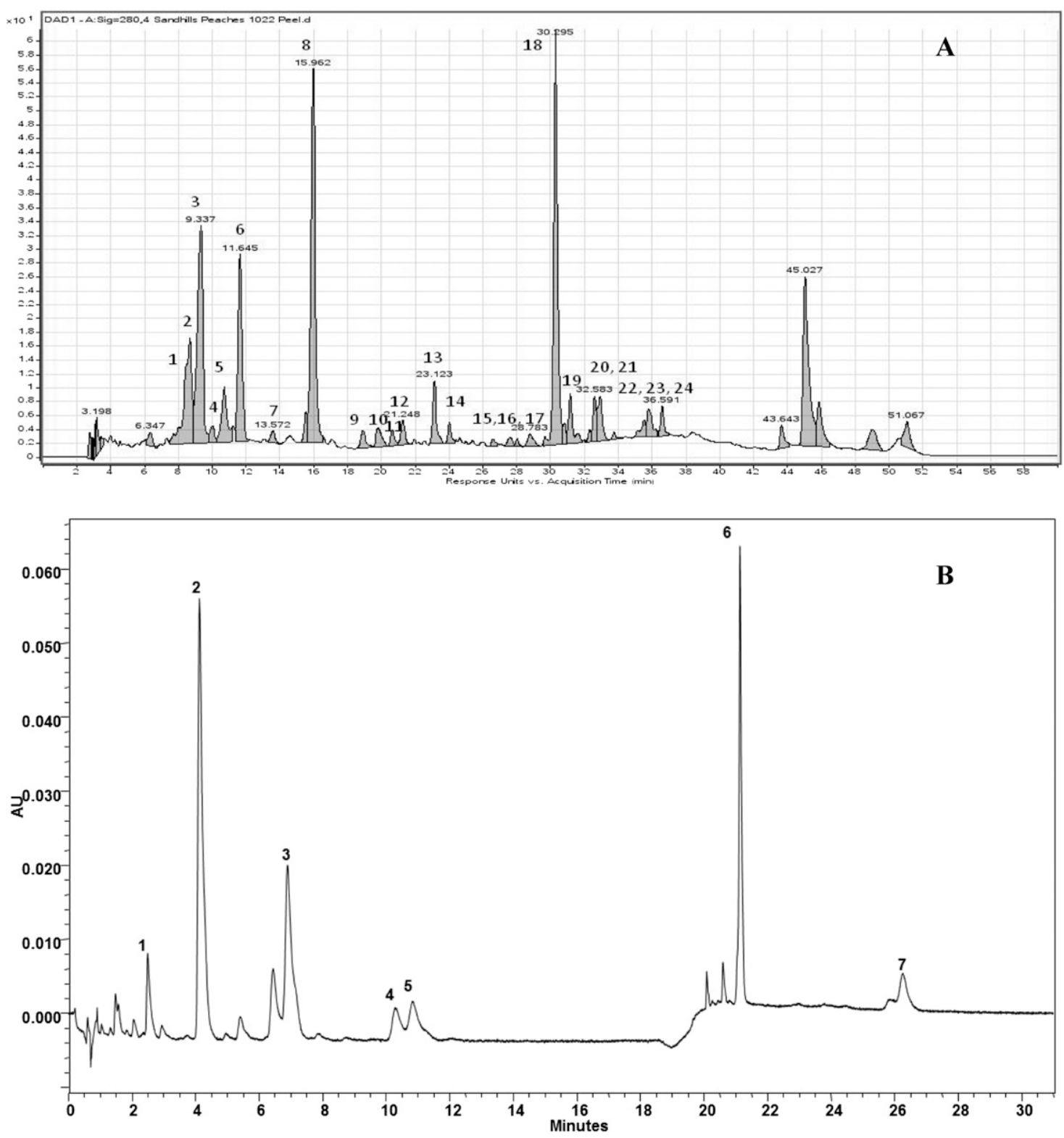

Fig. 2. Representative high-performance liquid chromatography chromatogram for 'Carolina Gold' peach showing the flavonoids (A) and carotenoids (B) detected and quantified in fruit peel. Peak compound identification: (A) flavan-3-ols (peaks 1. procyanidin B3, 3. B1, 5. B2, 6. catechin, 11. epicatechin, peaks 4, 7, 9, 10, 13, 14, 15, 16, and 17 are unidentified flava-3-ols), phenolic acids (peaks 2. neochlorogenic acid, 8. chlorogenic acid, and 12. caffiec acid), anthocyanins (peaks 18 . cyanidin-3-glucoside and 19. cyanidin-3-rutinoside), flavonol (peaks 20. quercitin-3-glucoside, 21. quercitin-3-rutinoside), peaks 22, 23, and 24. unidentified flavonols. (B) 1. neoxanthin, 2. violaxanthin, 3. lutein epoxide, 4. lutein, 5. zeaxanthin, 6. $\beta$-cryptoxanthin, 7. $\beta$-carotene.

$=0.76$; cyanidin 3-glucoside and cyanidin 3-rutinoside $=r=$ 0.78). A nonsignificant correlation was observed between the principle ANC (cyanidin 3-glucoside) and phenolic acid (cholorogenic acid) $(r=0.06)$. Correlations among individual carotenoids tended to be stronger than phenolics and ranged from $r=0.40$ to $r=0.87$ (Table 6).

\section{Discussion}

Polyphenolics were found in both the peel and flesh of peach (with the exception of ANC and select flavon-3-ols monomer and dimers found only in the peel) but occurred at significantly higher concentrations in the peel. Carotenoids were also detected in both tissues but were significantly more concen- trated in the fruit peel. We will confine the discussion to polyphenolics and carotenoids in the peel, but with the exception of ANC (which were only found in the peel), it should be noted that many of the same observations are relevant to both types of fruit tissues.

Given the nature of the plant material included in the study (white and yellow-fleshed peaches with and without red coloration in the peel), some of the results were not unexpected. Significant differences (3-fold) and genetic variation were observed in total carotenoid accumulation between yellow and white-fleshed cultivars. Our results are consistent with previous reports (Brandi et al., 2011), who observed that xanthophylls were the predominant carotenoids in peach at the fully ripe stage. In the white-fleshed cultivar China Pearl, all 
Table 1. Fruit characteristics and flavonoid and carotenoid concentrations in the peel of ripe peach fruit evaluated in two North Carolina locations over 2 years (2009 and 2010).

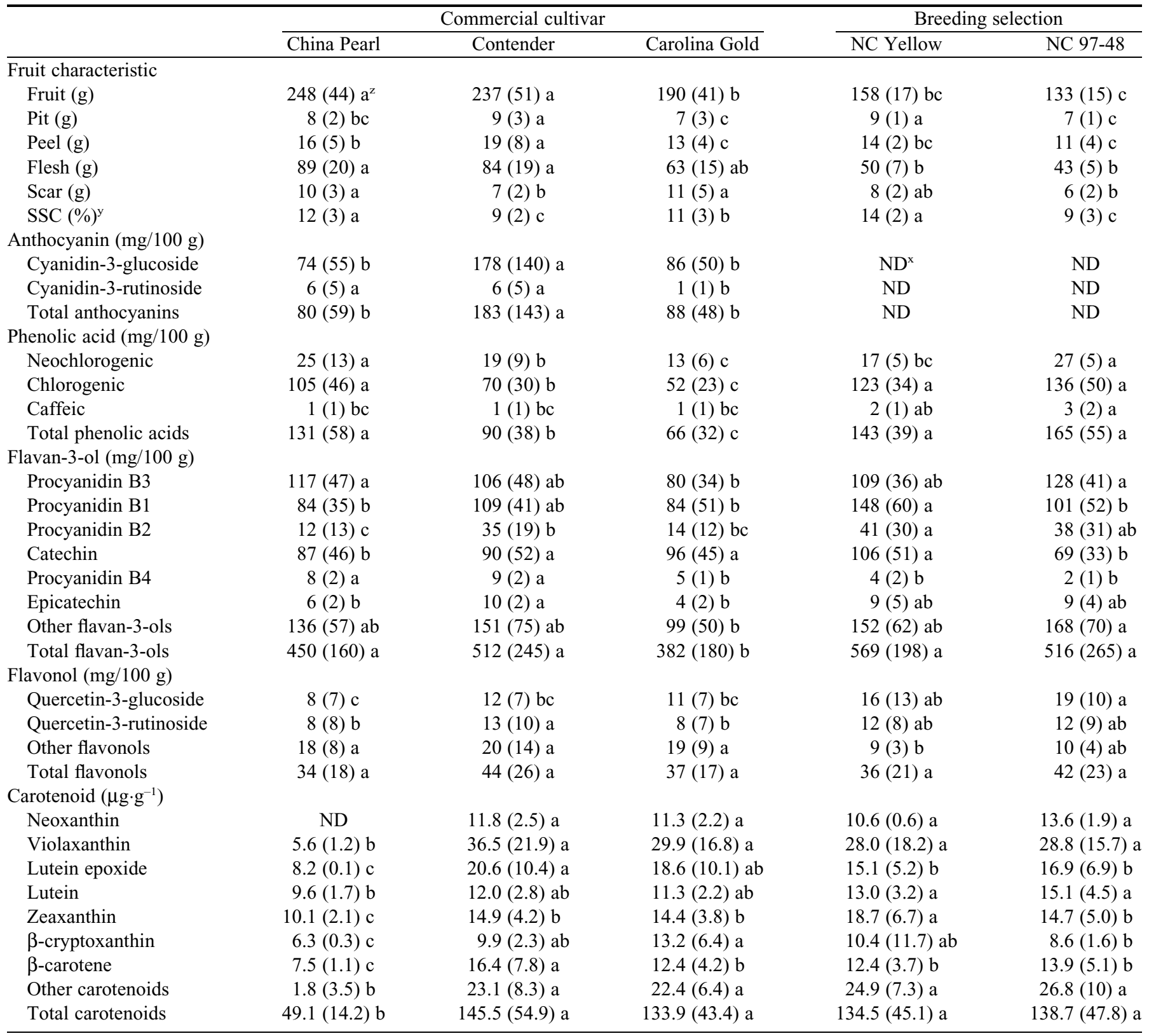

${ }^{\mathrm{z}}$ Means with different letters within rows are significantly different at $P<0.05$; values between parentheses following means are sD.

${ }^{\mathrm{y}}$ Soluble solid concentration.

Not detectable.

carotenoids (with the exception of neoxanthin) could be detected in the peel and the flesh. Although there were significant differences in all carotenoids between white and yellow-fleshed cultivars, the largest differences occurred in the xanthophylls (violaxanthin, neoxanthin, and lutein epoxide) and in the total accumulation of the three unidentified carotenoid peaks. Further examination of these unidentified peaks and comparison with previous spectra data suggest they likely represent isomers of mutatoxanthin, auroxanthin, and neochrome that have been previously described in peach (Brandi et al., 2011).

Yellow flesh color in peach is the result of a recessive mutation at the Y locus on linkage group 1 (Bliss et al., 2002). Recent reports suggest that mutations within the CCD4 carotenoid cleavage dioxygenase gene result in accumulation of yellowpigmented carotenoids and the subsequent reduction of apocarotenoids that likely contributes to aroma volatiles (Adami et al., 2013; Brandi et al., 2011; Falchi et al., 2013; Fukamatsu et al., 2013). This model is consistent with our observations, but the carotenoid levels observed in 'China Pearl' are higher than previously reported in white-fleshed cultivars (Brandi et al., 2011), which could be a function of environment, genetic background, or incomplete dominance at the $\mathrm{Y}$ locus. Based on coloration of the peel, we also expected to observe differences in ANC accumulation between the breeding selections lacking red color (NC 97-48 and NC Yellow) and cultivars that display 
Table 2. Flavonoid and carotenoid concentrations in the flesh of ripe peach fruit evaluated in two North Carolina locations over 2 years (2009 and 2010).

\begin{tabular}{|c|c|c|c|c|c|}
\hline & \multicolumn{3}{|c|}{ Commercial cultivar } & \multicolumn{2}{|c|}{ Breeding selection } \\
\hline & China Pearl & Contender & Carolina Gold & NC Yellow & NC 97-48 \\
\hline \multicolumn{6}{|l|}{ Anthocyanin (mg/100 g) } \\
\hline Cyanidin-3-glucoside & $\mathrm{ND}^{\mathrm{z}}$ & ND & ND & ND & ND \\
\hline Total anthocyanins & ND & ND & ND & ND & ND \\
\hline \multicolumn{6}{|l|}{ Phenolic acid (mg/100 g) } \\
\hline Neochlorogenic & $20(13) a b^{y}$ & $15(7) b$ & $13(7) b$ & $22(7) a b$ & $26(9) \mathrm{a}$ \\
\hline Caffeic & ND & ND & ND & ND & ND \\
\hline Total phenolic acids & $50(25) \mathrm{b}$ & $30(12) \mathrm{c}$ & $27(14) \mathrm{c}$ & $74(23) \mathrm{a}$ & 73 (39) a \\
\hline \multicolumn{6}{|l|}{ Flavan-3-ol (mg/100 g) } \\
\hline Procyanidin B3 & $77(40) a b$ & $55(25) b$ & $57(29) \mathrm{b}$ & $90(27) \mathrm{a}$ & $98(32) \mathrm{a}$ \\
\hline Procyanidin B1 & $26(20) c$ & $30(2) b c$ & $37(32) b$ & 75 (19) a & $35(21) b$ \\
\hline Procyanidin B2 & $4(3) b$ & $5(1) b$ & $5(2) b$ & $15(8) \mathrm{a}$ & $9(3) \mathrm{ab}$ \\
\hline Total flavan-3-ols & $215(118) a b$ & $177(95) b$ & $199(115) b$ & 343 (116) a & $277(160) \mathrm{a}$ \\
\hline \multicolumn{6}{|l|}{ Flavonol (mg/100 g) } \\
\hline Quercetin-3-glucoside & $5(5) b$ & $5(4) b$ & $11(9) \mathrm{a}$ & $2(1) b$ & $3(1) b$ \\
\hline Quercetin-3-rutinoside & trace & $5(3) a$ & $3(2) b$ & $3(2) b$ & $3(2) b$ \\
\hline Other flavonols & $1(0.2)$ & ND & $1(0.5)$ & ND & ND \\
\hline Total flavonols & $6(5) \mathrm{c}$ & $11(8) b$ & $15(9) \mathrm{a}$ & $5(3) \mathrm{c}$ & $6(3) \mathrm{c}$ \\
\hline \multicolumn{6}{|l|}{ Carotenoid $\left(\mu \mathrm{g} \cdot \mathrm{g}^{-1}\right)$} \\
\hline Neoxanthin & ND & $5.6(1.1) \mathrm{a}$ & $5.6(1.2) \mathrm{a}$ & $4.6(1.0) \mathrm{a}$ & $5.5(0.3) \mathrm{a}$ \\
\hline Violaxanthin & $2.4(0.5) \mathrm{b}$ & $19.5(11.5) \mathrm{a}$ & $14.1(7.1) \mathrm{a}$ & $20.3(9.6) \mathrm{a}$ & $16.6(9.6) \mathrm{a}$ \\
\hline Lutein epoxide & $4.3(0.7) b$ & $11.7(3.0) \mathrm{a}$ & $9.0(1.5) \mathrm{a}$ & $8.6(1.8) \mathrm{a}$ & $8.6(1.6) \mathrm{a}$ \\
\hline Lutein & $4.3(0.4) b$ & $6.7(7.1) \mathrm{a}$ & $6.8(4.4) \mathrm{a}$ & $6.6(3.4) \mathrm{a}$ & $7.1(2.9) \mathrm{a}$ \\
\hline
\end{tabular}

${ }^{\mathrm{z}}$ Not detectable.

${ }^{\mathrm{y}}$ Means with different letters within rows are significantly different at $P<0.05$; values between parentheses following means are SD.

significant red color in the same tissue ('Contender', 'China Pearl', and 'Carolina Gold'). The peel-specific ANC mutation in North Carolina peach germplasm has been designated $\mathrm{H}$ for Highlighter and differs from both ANC-less and white flower mutations previously described in peach (Beckman et al., 2005). In Rosaceae, MYB transcription factors (MYB10) regulate the transcription of UDP-glucose-flavonoid-3-O-glucosyltransferase (UFGT) and dihydroflavonol 4-reductase (DFR) genes and likely provide specific impact of ANC levels in the peel (Lin-Wang et al., 2010; Ravaglia et al., 2013).

The ANC content of 'China Pearl' and 'Carolina Gold' represents approximately half of what was observed in 'Contender'. Given the pedigrees of 'China Pearl' and 'Carolina Gold' (Fig. 1), this intermediate phenotype (between 'Contender' and mutants) could fit a model of additivity at a single locus, because 'China Pearl' is a progeny of 'Contender' and PI 134401 (peel colordeficient and likely double-recessive). 'Carolina Gold' also fits the model because it has an expected genetic contribution of $25 \%$ from Calanda San Miquel 2383 (peel color-deficient). Intermediate (pink) phenotypes in peach have been described in flower color mutations (Chaparro et al., 1995), but to our knowledge, this is the first time it has been observed in peel accumulation. Also of interest was the observation that although it represented a relatively minor contribution to overall ANC accumulation, cyanidin-3-rutinoside peel levels were statistically higher (6-fold) in 'Contender' and 'China Pearl' than they were in 'Carolina Gold'.

Our results suggest that the mutation for ANC accumulation does not impact the accumulation of flavonoids or phenolic acids. Chlorogenic acid concentration, in particular, appears to be independent of ANC accumulation as evidenced by both the ANOVA and the correlation analysis. Significant differences among cultivars were observed in chlorogenic acid accumulation over multiple years and locations, but these differences did not fit the same pattern observed for ANC accumulation. 'China Pearl', NC 97-48, and NC Yellow contained the highest levels of chlorogenic acid (123 to $136 \mathrm{mg} / 100 \mathrm{~g} \mathrm{DW}$ ), 'Carolina Gold' contained the lowest (52 mg/100 g DW), and 'Contender' represented an intermediate phenotype $(70 \mathrm{mg} / 100 \mathrm{~g} \mathrm{DW})$. 'Carolina Gold' also tended to have the lowest levels of overall flavan-3-ols, but these differences were not statistically significant. 
Table 3. Source of variation in fruit characteristics, flavonoids, and carotenoids measured in the ripe fruit peel of three peach cultivars ('China Pearl', 'Carolina Gold', and 'Contender') harvested at two North Carolina locations (Mills River and Jackson Springs) in 2009 and 2010.

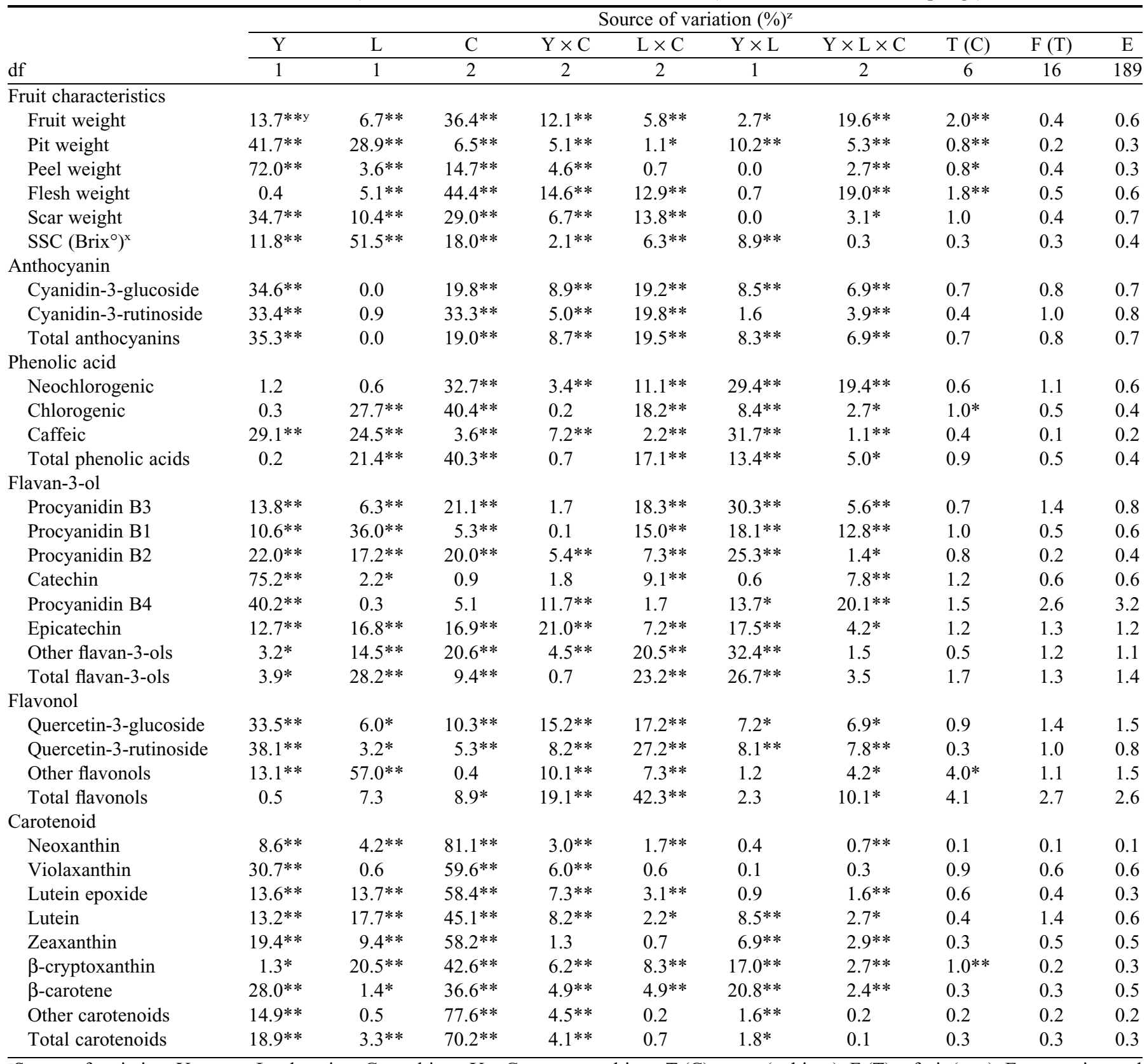

${ }^{\mathrm{z}}$ Source of variation: $\mathrm{Y}=$ year; $\mathrm{L}=$ location; $\mathrm{C}=$ cultivar; $\mathrm{Y} \times \mathrm{C}=$ year $\times$ cultivar; $\mathrm{T}(\mathrm{C})=$ tree $($ cultivar); $\mathrm{F}(\mathrm{T})=$ fruit $($ tree $) ; \mathrm{E}=$ experimental error.

${ }^{\mathrm{y}}$ Mean square values with * and ** are statistically significant at $P<0.05$ and $P<0.01$, respectively. The two mutants (NC 97-48 and NC Yellow) were not replicated in both locations; therefore, they were excluded from the analysis of variance table.

${ }^{\mathrm{x}} \mathrm{SSC}=$ soluble solid concentration.

Quercetin-3-glucoside was highest in ANC mutant advanced breeding lines NC 97-48 and NC Yellow, but this observation should be tempered by the fact that these cultivars were only grown in a single location over 2 years.

The ANOVA detected significant genetic variation among the three cultivars replicated over years and locations for all compounds except for the flavon-3-ol monomer catechin and the procyanidin B4. This suggests that even within commonly grown peach cultivars, significant variation exists for individual constituents of the polyphenol profile. Additionally, because all of the constituents contribute to chemical measurements of antioxidant capacity to varying degrees, selecting on the basis of these measurements could result in multiple phytochemical phenotypes with wide-ranging differences in the amounts of the individual compounds. It might also be a plausible explanation for why some phenolic-rich foods have beneficial impacts on health but these benefits do not directly correlate with antioxidant capacity. The results of the study demonstrate the importance of multiple years and locations for adequately evaluating the phytochemical profile of tree fruit. With respect 
Table 4. Source of variation in fruit characteristics, flavonoids, and carotenoids measured in the ripe fruit flesh of three peach cultivars ('China Pearl', 'Carolina Gold', and 'Contender') harvested at two North Carolina locations (Mills River and Jackson Springs) in 2009 and 2010.

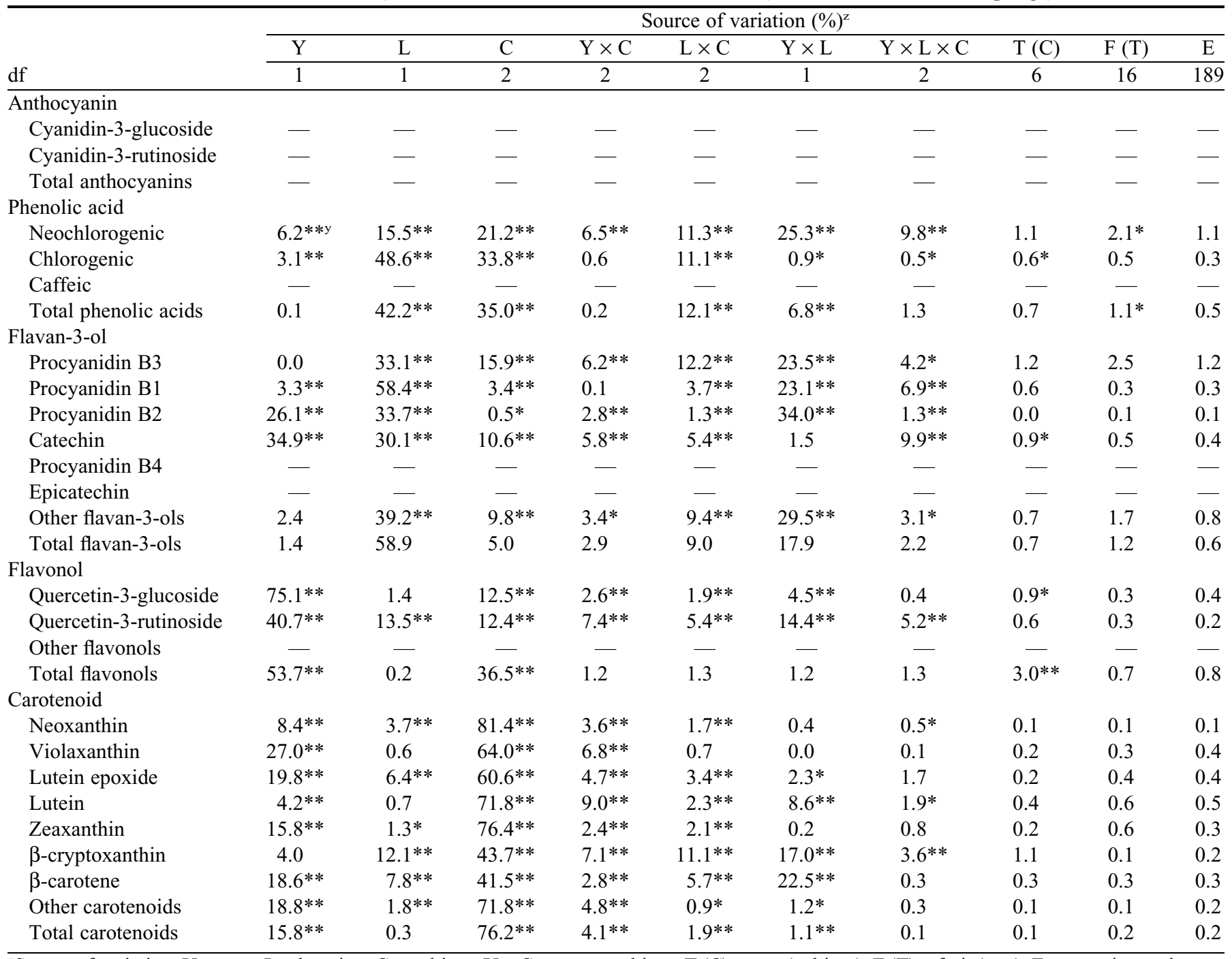

${ }^{\mathrm{z}}$ Source of variation: $\mathrm{Y}=$ year; $\mathrm{L}=$ location; $\mathrm{C}=$ cultivar; $\mathrm{Y} \times \mathrm{C}=$ year $\times$ cultivar; $\mathrm{T}(\mathrm{C})=$ tree (cultivar); $\mathrm{F}(\mathrm{T})=$ fruit $($ tree); $\mathrm{E}=$ experimental error. ${ }^{y}$ Mean square values with * and ** are statistically significant at $P<0.05$ and $P<0.01$, respectively. The two mutants (NC 97-48 and NC Yellow) were not replicated in both locations; therefore, they were excluded from the analysis of variance table.

to chlorogenic acid, $28 \%$ of the phenotypic variance was explained by location (year $=$ nonsignificant), whereas $35 \%$ of the phenotypic variation of ANC was explained by differences in years (location = nonsignificant). Analyzing fruit from the same environment over 2 years or from two locations in the same year would not have adequately accounted for variation associated with environment. Variation associated with location could be the result of differences in climate, soil fertility, temperature, cultivation, or (potentially) age differences of the trees at the two locations. Differences between locations and multiyear analysis provide for a more reliable estimation of the genetic variation. With respect to phenolic compounds, the percentage of observed genetic variance that we have observed (less than 40\%) would suggest that previous non-replicated surveys of these compounds should be treated as preliminary in nature and need to be followed up by more thorough analysis at multiple locations over multiple years.

The detailed phytochemical analysis of peach described in this publication serves multiple purposes. It provides an initial set of peach reference standard cultivars that can be used to identify additional material with unique profiles. Including these commonly grown cultivars in future surveys will provide baseline measurements that will allow meaningful comparisons to unrelated material. Second, the analyses provide evidence for genetic variation among related material that can be used to further investigate the genetics of phytochemical accumulation in peach. It should be noted that most commercially grown peach cultivars in the United States are derived from a narrow genetic base with almost all cultivars derived from an original 1860s introduction called Chinese Cling (Scorza et al., 1985). The variation detected among cultivars and advanced North Carolina breeding lines in this investigation may be a function of the diverse genetic background of the North Carolina peach breeding program, in which germplasm not related to Chinese Cling was often used to broaden the genetic base of the program. The previously described Highlighter gene may itself be relatively unique among peach cultivars. We have noted significant genetic variation among these cultivars for caroten- 
Table 5. Pearson's correlation coefficients for fruit characteristics and phenolic compounds measured in the peel of ripe peach fruit.

\begin{tabular}{|c|c|c|c|c|c|c|c|c|c|c|c|c|c|c|c|}
\hline \multicolumn{16}{|c|}{ Fruit characteristics and phenolic compounds ${ }^{z}$} \\
\hline & Pwt & $\mathrm{SSC}$ & B3 & $\mathrm{B} 1$ & B2 & Cat & B4 & Epicat & Nchlor & Chlor & Caff & Qgluc & Qrut & Cyglu & Cyrut \\
\hline Fwt & $0.58 * * y$ & 0.00 & 0.11 & -0.02 & -0.03 & 0.08 & 0.04 & -0.03 & 0.10 & 0.08 & -0.06 & -0.12 & $-0.15^{*}$ & -0.16 & 0.03 \\
\hline Pwt & & -0.10 & 0.02 & -0.13 & -0.06 & 0.12 & 0.01 & $-0.16^{*}$ & 0.01 & -0.10 & $-0.26 * *$ & -0.03 & $-0.28 * *$ & $-0.29 * *$ & $-0.23 * *$ \\
\hline B3 & & & & $0.54 * *$ & $0.39 * *$ & $0.55^{* *}$ & $0.31 * *$ & $0.55^{* *}$ & $0.89 * *$ & $0.83 * *$ & $0.44 * *$ & $0.35 * *$ & $0.38 * *$ & 0.16 & $0.37 * *$ \\
\hline B1 & & & & & $0.73 * *$ & $0.48 * *$ & $0.27 * *$ & $0.66^{* *}$ & $0.26^{* *}$ & $0.51^{* *}$ & $0.52 * *$ & 0.14 & $0.54 * *$ & $0.40 * *$ & $0.33 * *$ \\
\hline B2 & & & & & & 0.04 & 0.14 & $0.73 * *$ & $0.23 * *$ & $0.29 * *$ & $0.56 * *$ & 0.07 & $0.43 * *$ & $0.37 * *$ & $0.28 * *$ \\
\hline B4 & & & & & & & & $0.37 * *$ & 0.01 & $0.28 * *$ & 0.00 & $0.30 * *$ & 0.11 & 0.10 & $0.16^{*}$ \\
\hline Epicat & & & & & & & & & $0.37 * *$ & $0.53 * *$ & $0.67 * *$ & $0.34 * *$ & $0.50 * *$ & $0.42 * *$ & $0.45 * *$ \\
\hline Nchlor & & & & & & & & & & $0.76^{* *}$ & $0.46^{* *}$ & $0.20 * *$ & $0.29 * *$ & 0.06 & $0.36^{* *}$ \\
\hline Chlor & & & & & & & & & & & $0.60 * *$ & $0.35 * *$ & $0.45^{* *}$ & $0.21 * *$ & $0.55^{* *}$ \\
\hline Caff & & & & & & & & & & & & 0.14 & $0.40 * *$ & 0.13 & $0.39 * *$ \\
\hline Qgluc & & & & & & & & & & & & & $0.39 * *$ & $0.33 * *$ & $0.34 * *$ \\
\hline
\end{tabular}

${ }^{\mathrm{z} F w t}=$ fruit weight; Pwt $=$ fruit peel weight; SSC = fruit soluble solids; B3, B2, B1, B4 = procyanidins; cat = catechin; Epicat = epicatechin; Nchlor = neochlogenic acid; chlor = chlorogenic acid; caff = caffeic acid; Qgluc $=$ quercetin glucoside; Qrut $=$ quercetin rutinoside; Cyglu $=$ cyanidin-3-glucoside; Cyrut $=$ cyanidin-3-rutinoside.

y* and $* *$ are statically significant at $P<0.05$ and 0.01 , respectively (number of observations $=214$ ).

Table 6. Pearson's correlation coefficients for fruit characteristics and carotenoid compounds measured in the peel of ripe peach fruit.

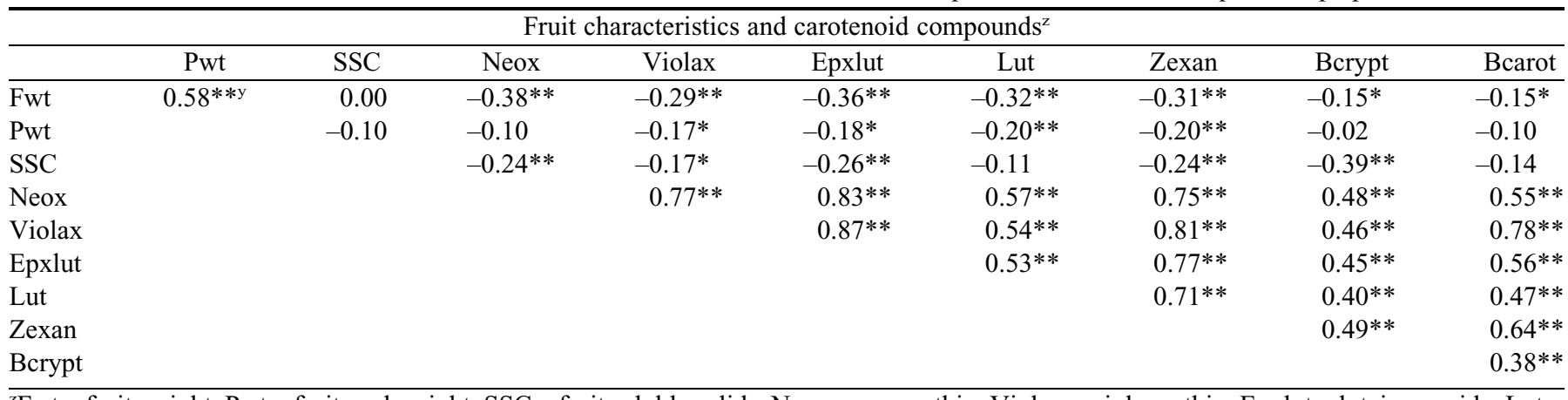

$\overline{{ }^{\mathrm{z}} \mathrm{Fwt}}=$ fruit weight; Pwt $=$ fruit peel weight; $\mathrm{SSC}=$ fruit soluble solids; Neox = neoxanthin; Violax = violaxanthin; Epxlut $=$ lutein epoxide; Lut = lutein; zexan $=$ zeaxanthin; Bcrypt $=\beta$-cryptoxanthin; Bcarot $=\beta$-carotene.

y* and $* *$ are statically significant at $P<0.05$ and 0.01 , respectively (number of observations $=214$ ).

oids, cyanidin-3-glucoside, cyanidin-3-rutinoside, chlorogenic acid, and individual flavan-3-ol monomers and dimers. Inclusion of this material into traditional linkage or association mapping studies should provide insight into how peach accumulates and partitions individual phytochemical compounds in a tissue-specific manner. Finally, because these cultivars differ significantly in individual components with putative health benefits and are widely grown, inclusion of the material in medical studies may provide additional evidence as to the bioactivity of the individual constituents and provide a clearer picture of the optimal phytochemical profile of peach.

\section{Literature Cited}

Adami, M., P. Franceschi, F. Brandi, A. Liverani, D. Giovannini, C. Rosati, L. Dondini, and S. Tartarini. 2013. Identifying a carotenoid cleavage dioxygenase (ccd4) gene controlling yellow/white fruit flesh color of peach. Plant Mol. Biol. Rpt. 31:1166-1175.

Arts, I.C. and P.C. Hollman. 2005. Polyphenols and disease risk in epidemiologic studies. Amer. J. Clin. Nutr. 81:317S-325S.
Beckman, T.G., J.R. Alcazar, W.B. Sherman, and D.J. Werner. 2005. Evidence for qualitative suppression of red skin color in peach. HortScience 40:523-524.

Bliss, F., S. Arulsekar, M. Foolad, V. Becerra, A. Gillen, M. Warburton, A. Dandekar, G. Kocsisne, and K. Mydin. 2002. An expanded genetic linkage map of Prunus based on an interspecific cross between almond and peach. Genome 45:520-529.

Brandi, F., E. Bar, F. Mourgues, G. Horvath, E. Turcsi, G. Giuliano, A. Liverani, S. Tartarini, E. Lewinsohn, and C. Rosati. 2011. Study of 'Redhaven' peach and its white-fleshed mutant suggests a key role of CCD4 carotenoid dioxygenase in carotenoid and norisoprenoid volatile metabolism. BMC Plant Biol. 11:24.

Cantín, C.M., M.A. Moreno, and Y. Gogorcena. 2009. Evaluation of the antioxidant capacity, phenolic compounds, and vitamin $\mathrm{C}$ content of different peach and nectarine [Prunus persica (L.) Batsch] breeding progenies. J. Agr. Food Chem. 57:4586-4592.

Chaparro, J.X., D.J. Werner, R.W. Whetten, and D.M. O'Malley. 1995. Inheritance, genetic interaction, and biochemical characterization of anthocyanin phenotypes in peach. J. Hered. 86:32-38.

Chong, M.F.F., R. Macdonald, and J.A. Lovegrove. 2010. Fruit polyphenols and CVD risk: A review of human intervention studies. Brit. J. Nutr. 104:S28-S39. 
Dalla Valle, A., I. Mignani, A. Spinardi, F. Galvano, and S. Ciappellano. 2007. The antioxidant profile of three different peaches cultivars (Prunus persica) and their short-term effect on antioxidant status in human. Eur. Food Res. Technol. 225:167-172.

de Pascual-Teresa, S., C. Santos-Buelga, and J.C. Rivas-Gonzalo. 2000. Quantitative analysis of flavan-3-ols in Spanish foodstuffs and beverages. J. Agr. Food Chem. 48:5331-5337.

Devore, E.E., J.H. Kang, M.J. Stampfer, and F. Grodstein. 2013. The association of antioxidants and cognition in the Nurses' Health Study. Amer. J. Epidemiol. 177:33-41.

Falchi, R., E. Vendramin, L. Zanon, S. Scalabrin, G. Cipriani, I. Verde, G. Vizzotto, and M. Morgante. 2013. Three distinct mutational mechanisms acting on a single gene underpin the origin of yellow flesh in peach. Plant J. 76:175-187.

Fukamatsu, Y., T. Tamura, S. Hihara, and K. Oda. 2013. Mutations in the CCD4 carotenoid cleavage dioxygenase gene of yellow-flesh peaches. Biosci. Biotechnol. Biochem. 77:2514-2516.

Gil, M.I., F.A. Tomás-Barberán, B. Hess-Pierce, and A.A. Kader. 2002. Antioxidant capacities, phenolic compounds, carotenoids, and vitamin $\mathrm{C}$ contents of nectarine, peach, and plum cultivars from California. J. Agr. Food Chem. 50:4976-4982.

Gordon, M.H. 2011. Significance of dietary antioxidants for health. Intl. J. Mol. Sci. 13:173-179.

Gu, L., M.A. Kelm, J.F. Hammerstone, G. Beecher, J. Holden, D. Haytowitz, S. Gebhardt, and R.L. Prior. 2004. Concentrations of proanthocyanidins in common foods and estimations of normal consumption. J. Nutr. 134:613-617.

Guzman, I., G.G. Yousef, and A.F. Brown. 2012. Simultaneous extraction and quantitation of carotenoids, chlorophylls, and tocopherols in Brassica vegetables. J. Agr. Food Chem. 60:7238-7244.

Halliwell, B. 1996. Antioxidants in human health and disease. Annu. Rev. Nutr. 16:33-50.

Haminiuk, C.W.I., G.M. Maciel, M.S.V. Plata-Oviedo, and R.M. Peralta. 2012. Phenolic compounds in fruits-An overview. Intl. J. Food Sci. Technol. 47:2023-2044.

Hollman, P.C.H., A. Cassidy, B. Comte, M. Heinonen, M. Richelle, E. Richling, M. Serafini, A. Scalbert, H. Sies, and S. Vidry. 2011. The biological relevance of direct antioxidant effects of polyphenols for cardiovascular health in humans is not established. J. Nutr. 141:989S-1009S.

Hong, Y.-J., D.M. Barrett, and A.E. Mitchell. 2004. Liquid chromatography/mass spectrometry investigation of the impact of thermal processing and storage on peach procyanidins. J. Agr. Food Chem. 52:2366-2371.
Lavelli, V., C. Pompei, and M.A. Casadei. 2009. Quality of nectarine and peach nectars as affected by lye-peeling and storage. Food Chem. 115:1291-1298.

Lin-Wang, K., K. Bolitho, K. Grafton, A. Kortstee, S. Karunairetnam, T. McGhie, R. Espley, R. Hellens, and A. Allan. 2010. An R2R3 MYB transcription factor associated with regulation of the anthocyanin biosynthetic pathway in Rosaceae. Plant Biol. 10:50.

Noratto, G., W. Porter, D. Byrne, and L. Cisneros-Zevallos. 2009. Identifying peach and plum polyphenols with chemopreventive potential against estrogen-independent breast cancer cells. J. Agr. Food Chem. 57:5219-5226.

Ravaglia, D., R. Espley, R. Henry-Kirk, C. Andreotti, V. Ziosi, R. Hellens, G. Costa, and A. Allan. 2013. Transcriptional regulation of flavonoid biosynthesis in nectarine (Prunus persica) by a set of R2R3 MYB transcription factors. BMC Plant Biol. 13:68.

Rodriguez-Amaya, D.B. 2001. A guide to carotenoid analysis in foods. Intl. Life Sci. Inst. Press, Washington, DC.

Russnes, K.M., K.M. Wilson, M.M. Epstein, J.L. Kasperzyk, M.J. Stampfer, S.A. Kenfield, S. Smeland, R. Blomhoff, E.L. Giovannucci, W.C. Willett, and L.A. Mucci. 2014. Total antioxidant intake in relation to prostate cancer incidence in the health professionals followup study. Intl. J. Cancer 134:1156-1165.

Scorza, R., S. Mehlenbacher, and G. Lightner. 1985. Inbreeding and coancestry of freestone peach cultivars of the eastern United States and implications for peach germplasm improvement. J. Amer. Soc. Hort. Sci. 110:547-552.

Tomás-Barberán, F.A., M.I. Gil, P. Cremin, A.L. Waterhouse, B. HessPierce, and A.A. Kader. 2001. HPLC-DAD-ESIMS analysis of phenolic compounds in nectarines, peaches, and plums. J. Agr. Food Chem. 49:4748-4760.

Vauzour, D., A. Rodriguez-Mateos, G. Corona, M.J. Oruna-Concha, and J.P.E. Spencer. 2010. Polyphenols and human health: Prevention of disease and mechanisms of action. Nutrients 2:1106-1131.

Vizzotto, M., L. Cisneros-Zevallos, D.H. Byrne, D.W. Ramming, and W.R. Okie. 2007. Large variation found in the phytochemical and antioxidant activity of peach and plum germplasm. J. Amer. Soc. Hort. Sci. 132:334-340.

Werner, D., J. Ballington, and D. Ritchie. 1989. 'Contender' peach. HortScience 24:159-160.

Werner, D.J. and W.R. Okie. 1998. A history and description of the Prunus persica plant introduction collection. HortScience 33:787793.

Werner, D.J. and L.K. Snelling. 2006. Peach tree named 'Carolina Gold’. U.S. Plant Patent US20060112470 P1. U.S. Patent Trademark Office, Washington, DC. 